\title{
Three new species of Cleradini from Australia (Hemiptera: Heteroptera: Rhyparochromidae)
}

\author{
M. B. MALIPATIL ${ }^{12} \&$ M. J. BLACKET ${ }^{1}$ \\ 1 Department of Primary Industries, Knoxfield Centre, Private Bag 15, Ferntree Gully Delivery Centre, Vic. 3156, Australia. \\ E-mail: mallik.malipatil@dpi.vic.gov.au \\ 2 La Trobe University, Bundoora, Vic. 3086, Australia.
}

\begin{abstract}
Neoclerada parainsulicola sp. nov., Paramahisa kununurraensis sp. nov., and Laticlerada tasmanica sp. nov., have been described and illustrated. Cleradini are generally found in tropical habitats; the first two new species are described from tropical northern Australia, whereas the last species is the first record of Cleradini for cool temperate Tasmania.
\end{abstract}

Key words: Taxonomy, new taxa, descriptions, diagnoses, distribution, Tasmania

\section{Introduction}

A taxonomic revision of Australian Cleradini (family Rhyparochromidae, formerly Lygaeidae) was conducted by Malipatil (1981), who subsequently reviewed the world Cleradini and provided a cladistic analysis of relationships within the tribe (Malipatil 1983). Since then no new Australian species have been described (see also Slater \& O’Donnell 1995; Cassis \& Gross 2002). However, one new name, Laticlerada nidicolloides Slater \& O'Donnell, 1995, was published for Horváth's (1909) male Clerada laticollis after Bergroth's (1914) Clerada nidicola was synonymised by Malipatil (1981) with Horváth's female Clerada laticollis. Horváth's type series comprised two species.

Among the further specimens that have now become available, three undescribed species, Neoclerada parainsulicola sp. nov., Paramahisa kununurraensis sp. nov., and Laticlerada tasmanica sp. nov. have been discovered and are described in this paper; the last mentioned species is the first record of Cleradini for cool temperate Tasmania. Two of the three species described in this paper have been based on single specimens, and it is to be hoped that this will prompt the discovery of further specimens of these predominantly tropical (Malipatil 1983) and almost exclusively mammal-nest associated bugs (Sweet 1967).

The present contribution brings the total number of cleradine species known from Australia to 26 in six genera.

\section{Materials and methods}

Details of male and female genitalia dissection methods and terminologies used in this article are those given in Malipatil (1978). Measurements are expressed in millimetres.

Composite automontage images of all habitus and other details of the body and genitalia characters were obtained with a M205C Leica microscope and camera using the Leica Application Suite software (version 3.4.0).

Repositories of specimens examined in this study: MV, Museum Victoria, Melbourne; TM, Tasmanian Museum, Hobart; VAIC, Victorian Agricultural Insect Collection, Department of Primary Industries, Knoxfield / Bundoora. 


\section{Taxonomy}

Neoclerada parainsulicola sp. nov. (Figs. 1-11)

Specimens examined: Holotype male, Nourlangie Creek, 12.52S 132.47E, $8 \mathrm{~km}$ E of Mt Cahill, 17.xi.1972, T.Weir \& A. Allwood, in MV. Paratype, one male, Koongarra, 12.52S 132.50E, 15 km E of Mt Cahill, 15.xi.1972, T. Weir \& A. Allwood, dissected, in VAIC.

\section{Description:}

Colour: Body above (Fig. 1) and below, labium, and 1st segment of antenna, dark brownish-ochraceous. Eyes red-fuscous. Proximal third to half of 4th segment whitish (Fig. 5). With the following dark brown: 2nd, 3rd and remainder of 4th antennal segments, scutellum, part of inner margin of clavus, a broad almost round discal patch on corium interior and narrowly exterior to $\mathrm{R}+\mathrm{M}$, and parts of membrane. Disc of abdominal venter luteous.

Structure: Measurements are of holotype followed by those of paratype within round brackets. Body flat above, obovate in outline, gradually widened from head end; corium abruptly widened near middle, then gradually narrowing posteriorly. Body length including wings 5.40 (6.20); maximum width 2.39 (2.66).

Head: Gradually narrowed from base to apex (Fig. 3); tylus rounded and well exceeding jugae, these narrowed; antennifers slightly projecting anterolaterad; ocelli small, clear; bucculae very short, not extending posteriorly to level of antennifers; head ventrally and medianly shallowly grooved to base; head above corrugated, punctured similar to pronotum. Length of head 1.05 (1.10); width across eyes $0.78(0.82)$; interocular space 0.37 (0.39); interocellar space $0.48(0.50)$; eye-ocellar space $0.04(0.05)$; eye length $0.32(0.32)$; eye width $0.20(0.20)$. Antennae (Fig. 5) slender, geniculate, 4th segment longest; 1st segment with half of its length extending beyond apex of head; length of segments: I 0.50 (0.60); II 0.92 (1.03); III 0.39 (0.41); IV 1.15 (missing). Labium (Fig. 4) reaching mid coxae, 1st segment extending to about middle of head, 2nd segment to base of head; length of segments: I 0.57 (0.62); II 0.41 (0.41); III 1.01 (1.01); IV 0.28 (0.30).

Thorax: Pronotum (Fig. 2) with well demarcated anterior collar; lateral margins distinctly sinuate near middle, broadly carinate, and slightly reflexed upwards; posterior margin straight; disc with 3 depressed areas. Entire surface almost uniformly punctured similar to dorsum of head; median length 0.85 (0.90); width at posterior margin 1.65 (1.80). Metathoracic scent gland auricle prominently projecting above pleural surface, orifice directed posteriorly. Legs slender; fore femora only slightly thicker than other femora, unarmed below; tibiae slender; hind basitarsus about $2 \mathrm{x}$ as long as distal 2 segments combined. Scutellum with a distinct median laevigate ridge; length 0.82 (0.92); width 1.03 (1.03). Clavus with coarse punctures as follows: an almost complete inner row adjoining corial margin, an almost complete middle row, and the area between middle row and claval anal margin covered with unevenly spaced punctures; claval commissure 0.96 (1.15). Corium with Sc distinctly depressed and reflexed along lateral margins which are narrowed in proximal quarter, then explanately widened to about middle of corium, thereafter gradually narrowed posteriorly; punctate as follows: 2 more or less complete parallel rows adjoining claval margin (with an incomplete row between), 1 or 2 short incomplete rows exterior to outer row; remainder of corium covered with uniform, but unevenly spaced punctures. Length of hemelytra 3.68 (4.14); length of corium 3.17 (3.54); width of membrane 1.33 (1.27). Hind wings not examined.

Abdomen: Dorsally flat, ventrally sterna medianly keeled (Fig. 7), subshiny; submedian trichobothria on stenum III in triangular series and those of sternum IV in rectilinear series; trichobothrial areas rugulose and raised above surface; intersegmental suture between III-IV curved forward well before margin, but suture distinct on margin. Lateral tergites distinct (Fig. 6). Terga mostly membranous; sclerotised as follows (Fig. 6): a narrow area around anterior, and a larger area around middle, scent gland scars, and a broad median plate on posterior of tergum $\mathrm{V}$ enclosing posterior scar and extending to end of abdomen. Anterior scent gland scar slightly wider than posterior two scars which are equal in width.

Male: Pygophore as in Fig. 8, dorsally with well developed processes above base of parameres. Paramere (Fig. 9) with blade forked, inner tooth slightly longer and larger than outer tooth; subbasal process broad and prominent. Aedeagus (Figs. 10,11) without lobes or processes on conjunctiva and vesica; phallotheca lightly uniformly sclerotised; ejaculatory reservoir reduced; helicoid process with about 2 coils, gonoporal process with $4-5$ coils; basal coils tighter than apical coils; secondary gonopore slightly flaring.

Female: Unknown.

Distribution. Northern Territory of Australia. 


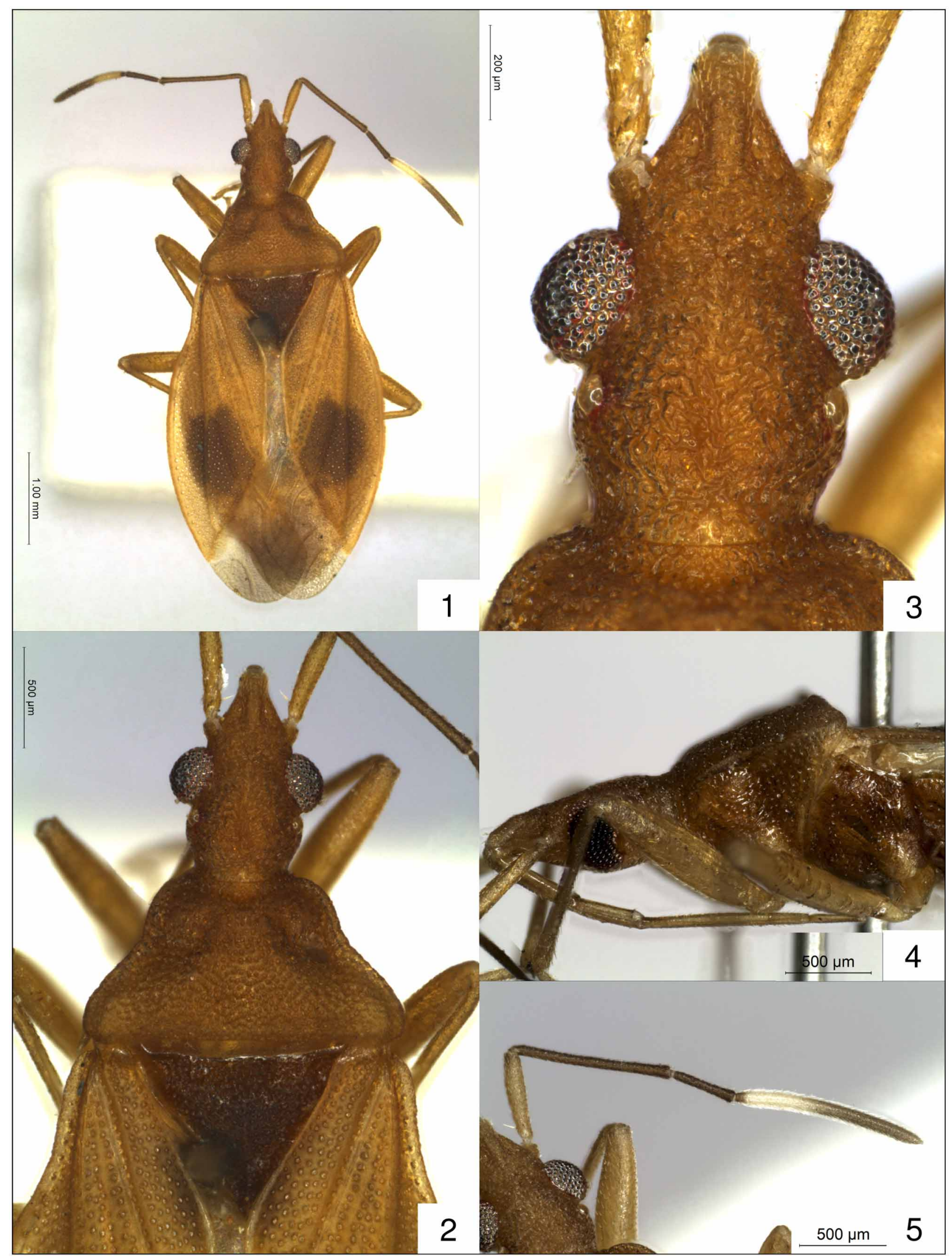

FIGURES 1-5. Neoclerada parainsulicola: 1, habitus holotype male; 2, anterior part of body, dorsal view; 3, head, enlarged, dorsal view; 4, anterior part of body, lateral view; 5, antenna. 
Diagnosis. Neoclerada parainsulicola is closest to another Northern Territory species, N. insulicola Malipatil, but differs from it in colour, particularly the two large, rather round brown spots on the coria (Fig. 1) and the lighter membrane (apical half of corium interior to $\mathrm{R}+\mathrm{M}$, and entire membrane, in $N$. insulicola are dark brown), the more explanate and reflexed lateral margins of the corium, and the broad subbasal process on paramere (apically narrowed subbasal process in $N$. insulicola). In general colour, $N$. parainsulicola resembles the widely distributed Clerada apicicornis Signoret (Figs. 12-16), but differs from it in several major generic characters including the round-sided postocular part of the head (Fig. 3 compared with Fig. 14) and the forked paramere blade shown in Fig. 9 (not forked in C. apicicornis, see Malipatil 1981).

Etymology. The species name alludes to its similarity with the species Neoclerada insulicola Malipatil.

Notes. Neoclerada (now comprising three species) is only known from northern Australia (Malipatil 1983, and the present study).

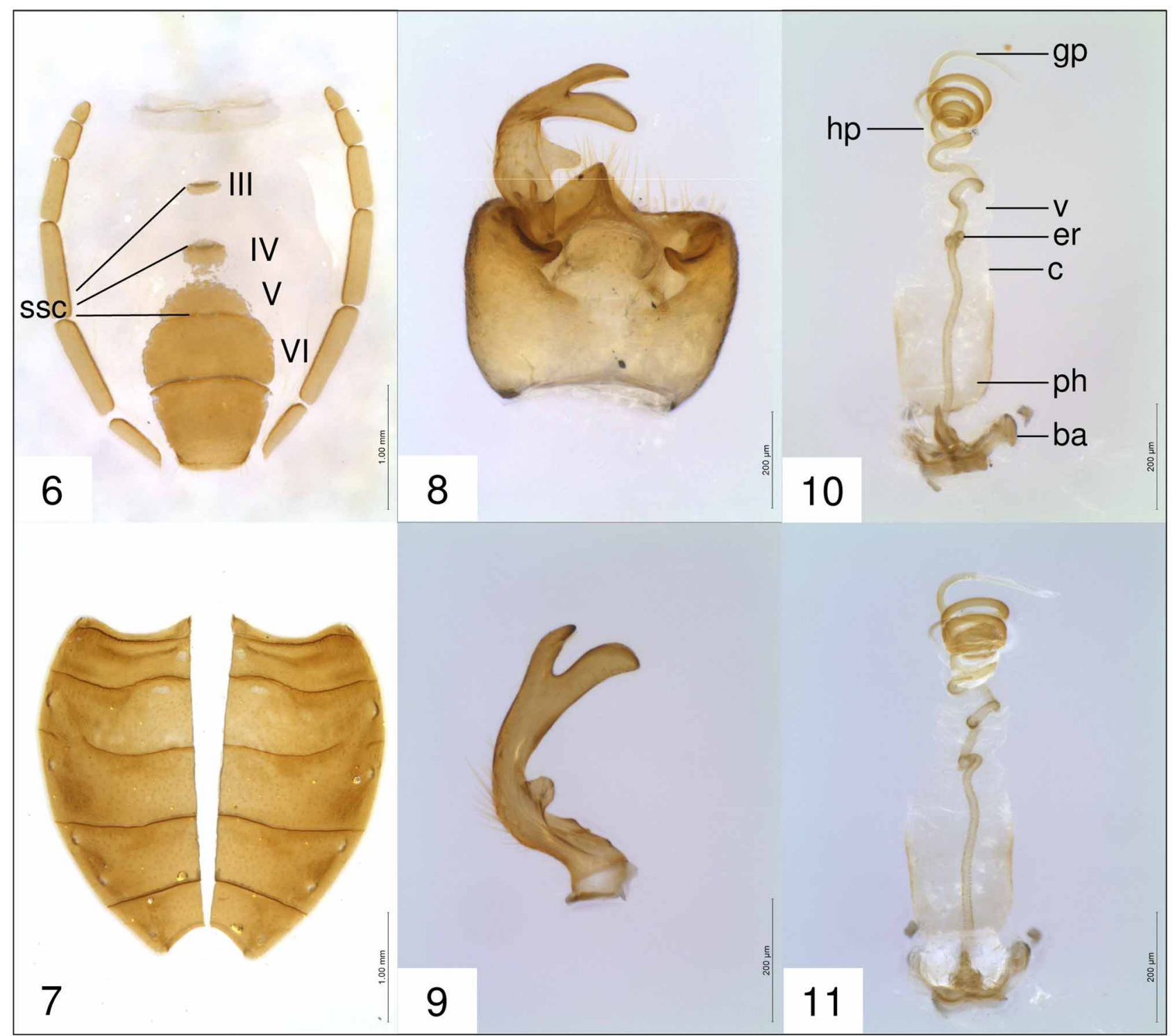

FIGURES 6-11. Neoclerada parainsulicola paratype male: 6, abdominal tergum; 7, abdominal sternum; 8, pygophore, dorsal view with right paramere in situ; 9, left paramere, ventral view; 10, aedeagus, dorsal view; 11, aedeagus, ventral view. Abbreviations: ba, basal apparatus; c, conjunctiva; er, ejaculatory reservoir; hp, helicoid process; gp, gonoporal process; ph, phallosoma; ssc, scent gland scar; v, vesica. 


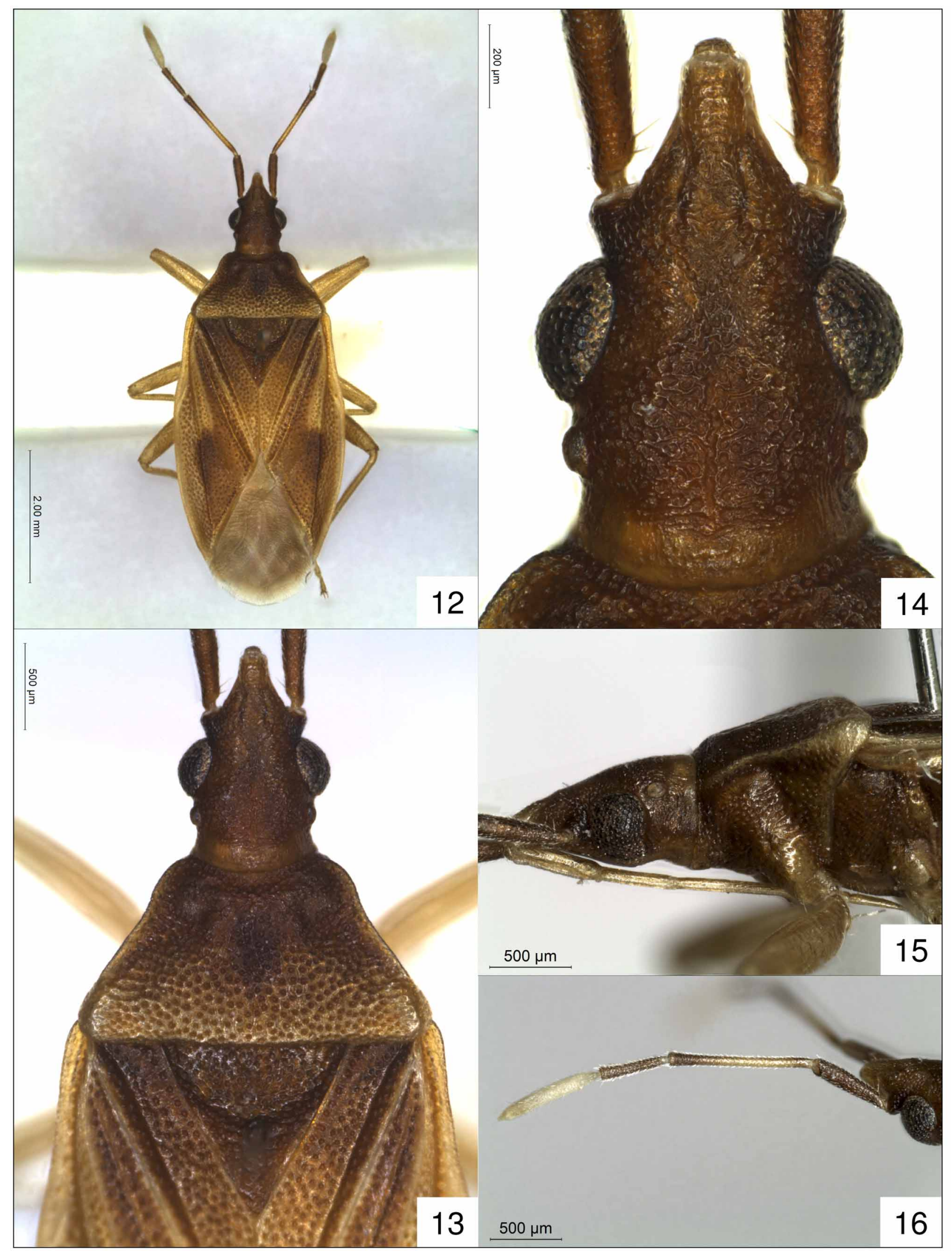

FIGURES 12-16. Clerada apicicornis: 12, habitus male; 13, anterior part of body, dorsal view; 14, head, enlarged, dorsal view; 15, anterior part of body, lateral view; 16, antenna. Specimen examined: male, Sydney, New South Wales, 1976, H.A. Rose, in VAIC. 
Specimen examined: Holotype male, 4th segment of left antenna missing, Kununurra, Western Australia, 13.xii.1983, A. Postle, in MV.

\section{Description:}

Colour: Body (Fig. 17) above dark reddish-brown; with narrow lateral margins of corium, and 3 broad unevenly spaced spots on posterior margin of pronotum, red. Labium, 1st segment of antennae and legs, uniformly yellowish-brown; 2nd, 3rd and distal quarter of 4th segment of antennae darker than 1st segment; remainder of 4th segment white. Trichobothrial areas on abdominal venter reddish-yellow.

Structure: Measurements are of holotype. Body matt, elongate ovate, with long and slender antennae and legs. Head above, pronotum, scutellum and clavus and corium covered with sparse, long, dark bristles, borne on indistinct bases (Figs. 17-20). Body length including wings 6.80; maximum width 2.30.

Head: Above indistinctly corrugated (Fig. 19), not punctate similar to pronotum, subshiny; bucculae ending before base of antennifers; head ventrally and medianly not grooved to base of head. Length of head 1.38; width across eyes 0.92 ; interocular space 0.46 ; interocellar space 0.67 ; eye-ocellar space 0.04 ; eye length 0.34 ; eye width 0.23. Antennae (Fig. 21) long, slender, 2nd segment longest; 1st segment with half of its length extending beyond apex of head; 4th segment slightly curved over entire length; length of segments: I 0.69; II 1.61; III 0.87; IV 1. 30. Labium (Fig. 20) almost reaching hind coxae; 1st segment extending to about middle of head, 2nd segment to beyond base of head; length of segments: I 0.85; II 0.65; III 1.49; IV 0.33.

Thorax: Pronotum (Fig. 18) with well demarcated anterior collar; lateral margins distinctly sinuate near middle; posterior margin straight; anterior lobe area slightly swollen compared with posterior lobe area. Entire surface except calli area almost uniformly and sparsely punctate with shallow punctures, the space between punctures wider than the punctures themselves; median length 0.92 ; width at posterior margin 1.72 . Thoracic pleura without erect bristles. Metathoracic scent gland auricle prominently projecting above pleural surface, orifice directed posteriorly. Legs slender, long; fore femora only slightly thicker than other femora, armed below with two widely spaced rows each of 6 or 7 long sparse setae with slightly tuberculate bases; other femora with only an inner row of 6 or 7 shorter setae; tibiae slender; hind basitarsus about $2.75 \mathrm{x}$ as long as distal 2 segments combined. Scutellum with an indistinct median laevigate ridge, sparsely and irregularly punctate all over; length 0.87 ; width 0.96. Claval commissure 0.97 . Corium with Sc indistinctly depressed, sides almost parallel throughout, punctate as in P. trimaculata Malipatil. Length of hemelytra 4.14; length of corium 3.22; width of membrane 1.25. Hind wings not examined.

Abdomen: Dorsally flat, ventrally medianly keeled (Fig. 23), subshiny, without a distinct stridulitrum; submedian trichobothria on stenum III in triangular series and those of sternum IV in rectilinear series; trichobothrial areas rugulose and raised above surface; intersegmental suture between III - IV curved indistinctly forward well before margin. Lateral tergites narrow (Fig. 22). Terga mostly membranous, with gradually widened broad median patch from posterior of anterior scent gland scar to end of abdomen sclerotised as in Fig. 22; a few bristles on posterior margin of 7th tergum. Anterior scent gland scar slightly wider than posterior two scars, these equal in width.

Male: Pygophore as in Fig. 24, with well developed processes above base of parameres. Paramere (Fig. 25) rather short and stumpy, with blade forked, both teeth of about equal size and length; subbasal inner process broad and prominent. Aedeagus (Figs. 26, 27) without lobes or processes on membranous conjunctiva and vesica; phallotheca moderately pigmented particularly on sides; ejaculatory reservoir reduced; duct distal to ejaculatory reservoir distinctly thicker and heavily sclerotised; helicoid process with about 2 coils, gonoporal process with 4-5 coils; basal coils tighter than apical coils; secondary gonopore slightly flaring.

Female: Unknown.

Distribution. Western Australia.

Diagnosis. Paramahisa kununurraensis is similar to P. trimaculata Malipatil in having bristles on head, pronotum and hemelytra, and three reddish spots on posterior margin of pronotum (Figs. 18-20). However, $P$. kununurraensis is distinguished from $P$. trimaculata by the uniformly yellowish-brown legs (Fig. 17), (almost black in P. trimaculata), and by the equal size, but unequal spacing, of the three red spots on posterior pronotal margin (Fig. 18).

Etymology. This species is named after the type locality. 


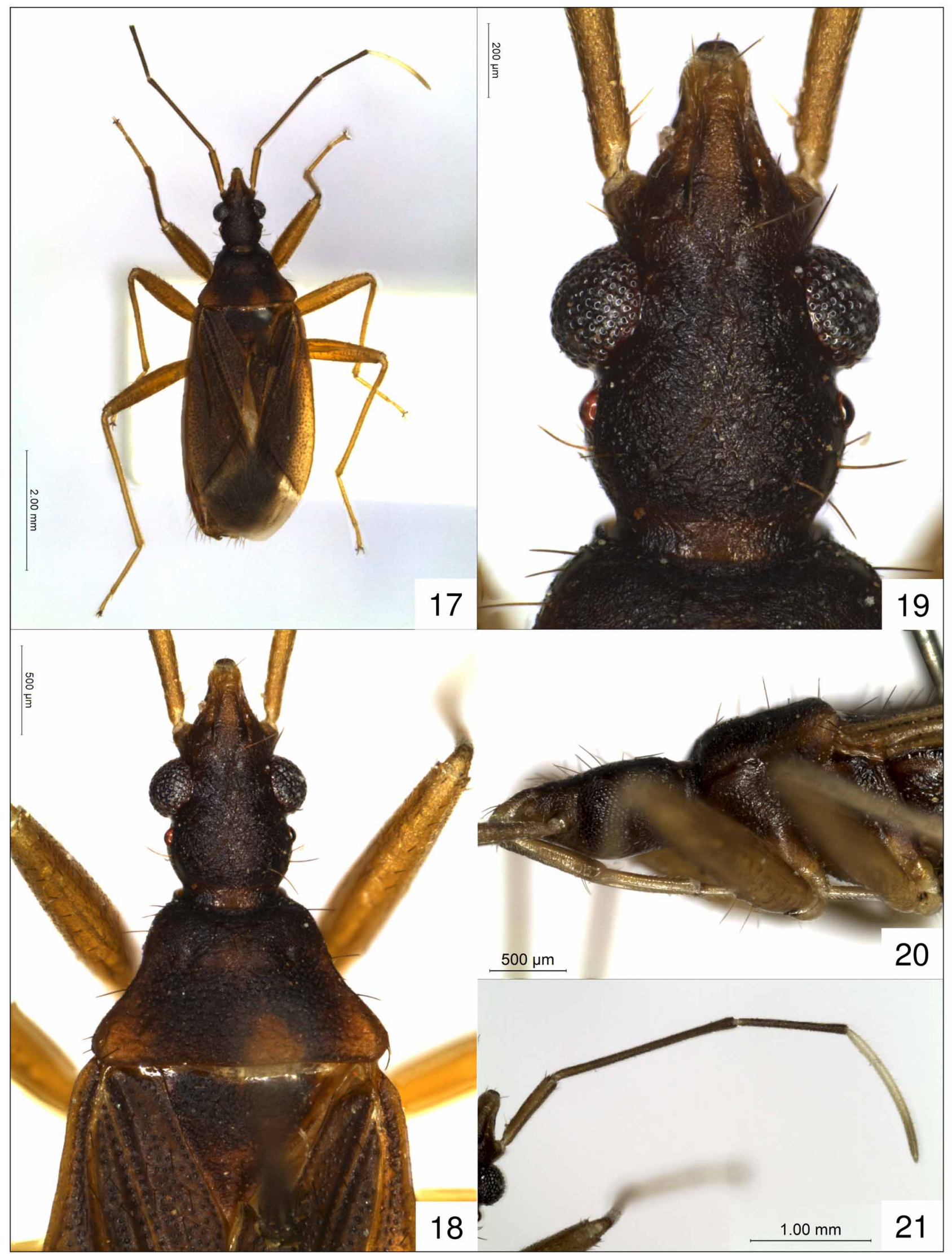

FIGURES 17-21. Paramahisa kununurraensis: 17, habitus holotype male; 18, anterior part of body, dorsal view; 19, head, enlarged, dorsal view; 20, anterior part of body, lateral view; 21, antenna. 


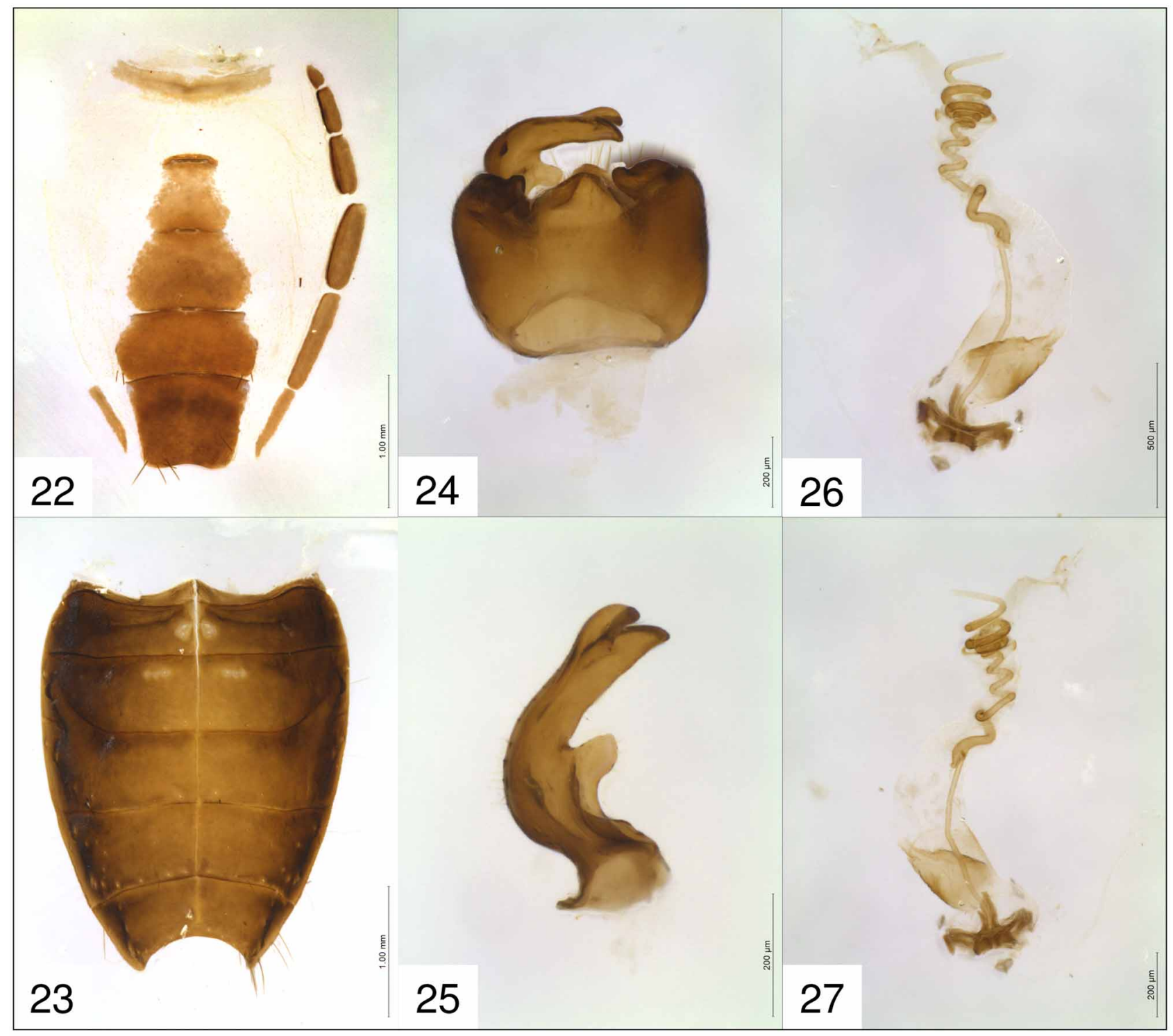

FIGURES 22-27. Paramahisa kununurraensis holotype male: 22, abdominal tergum (lateral tergites of left side missing); 23, abdominal sternum; 24, pygophore, dorsal view with right paramere in situ; 25, left paramere, ventral view; 26, aedeagus, dorsal view; 27, aedeagus, ventral view.

Notes. Paramahisa (now comprising ten species) is mostly known from north-eastern Australia (Malipatil 1983, and the present study), $P$. kununurraensis is the second species to be described from Western Australia. $P$. trimaculata is only known from two female Queensland specimens (Malipatil 1981), whereas P. kununurraensis is described here from a single male.

Laticlerada tasmanica sp. nov. (Figs. 28-37)

Specimen examined: Holotype female, Tasmania, Coles Bay, M.V. [mercury vapour light], 5.iii.1989, L. Hill, in TM.

\section{Description:}

Colour: Body (Fig. 28) and appendages (except 4th antennal segment) ferruginous-black; 4th segment lighter than other segments, light brown, particularly in basal area. Pronotum with humeral angles, and a narrow area along posterior margin, reddish-orange; membrane with paler blotches; coxae, trochanters, apices of femora, most of tibiae, and tarsi reddish brown; claws fuscous. Abdomen below reddish-orange; postero-medial area of last visible abdominal sternum (VI) blackish in triangular form on either side of median cleft (see Fig. 34). 


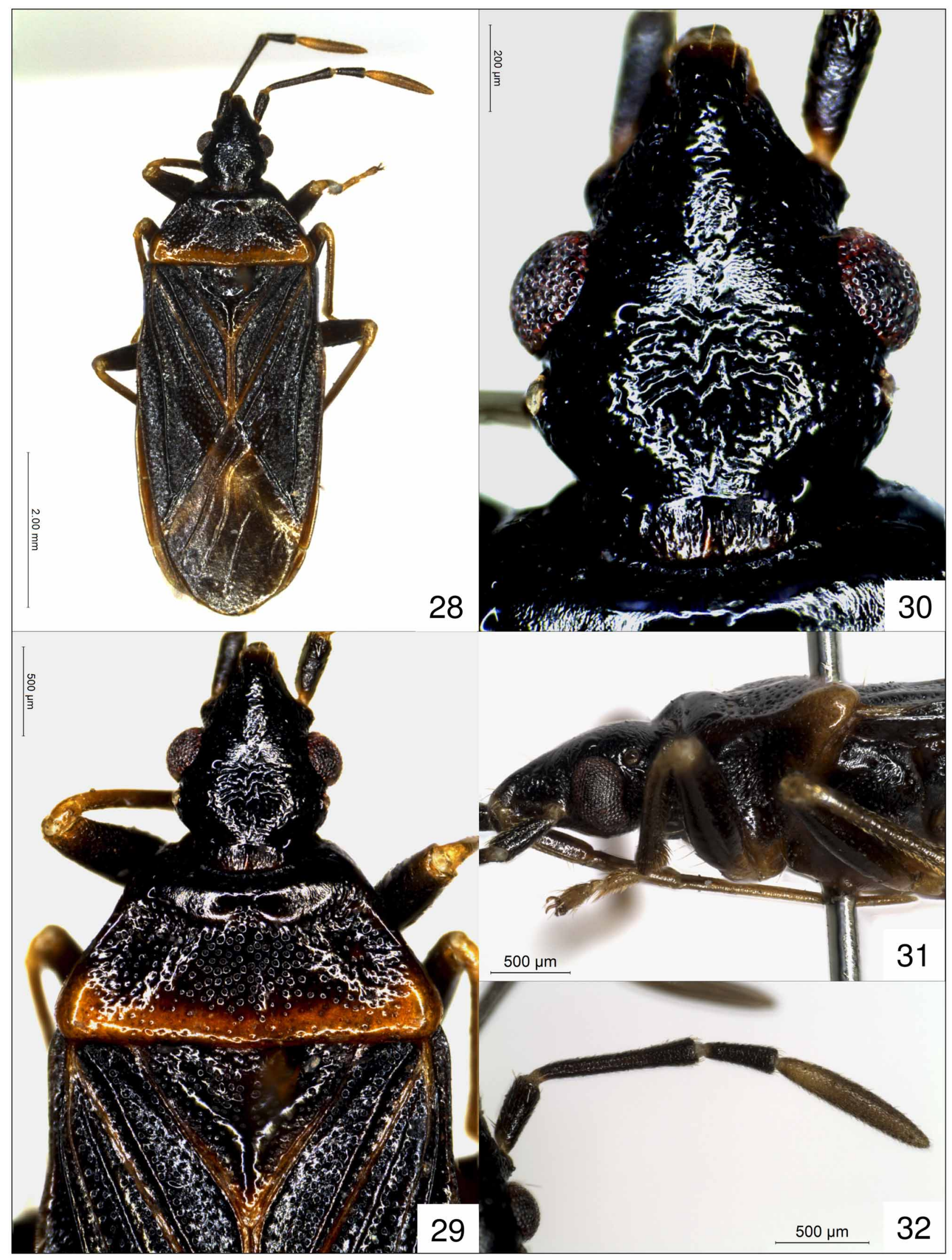

FIGURES 28-32. Laticlerada tasmanica: 28, habitus holotype female; 29, anterior part of body, dorsal view; 30, head enlarged dorsal view; 31, anterior part of body, lateral view; 32, antenna. 


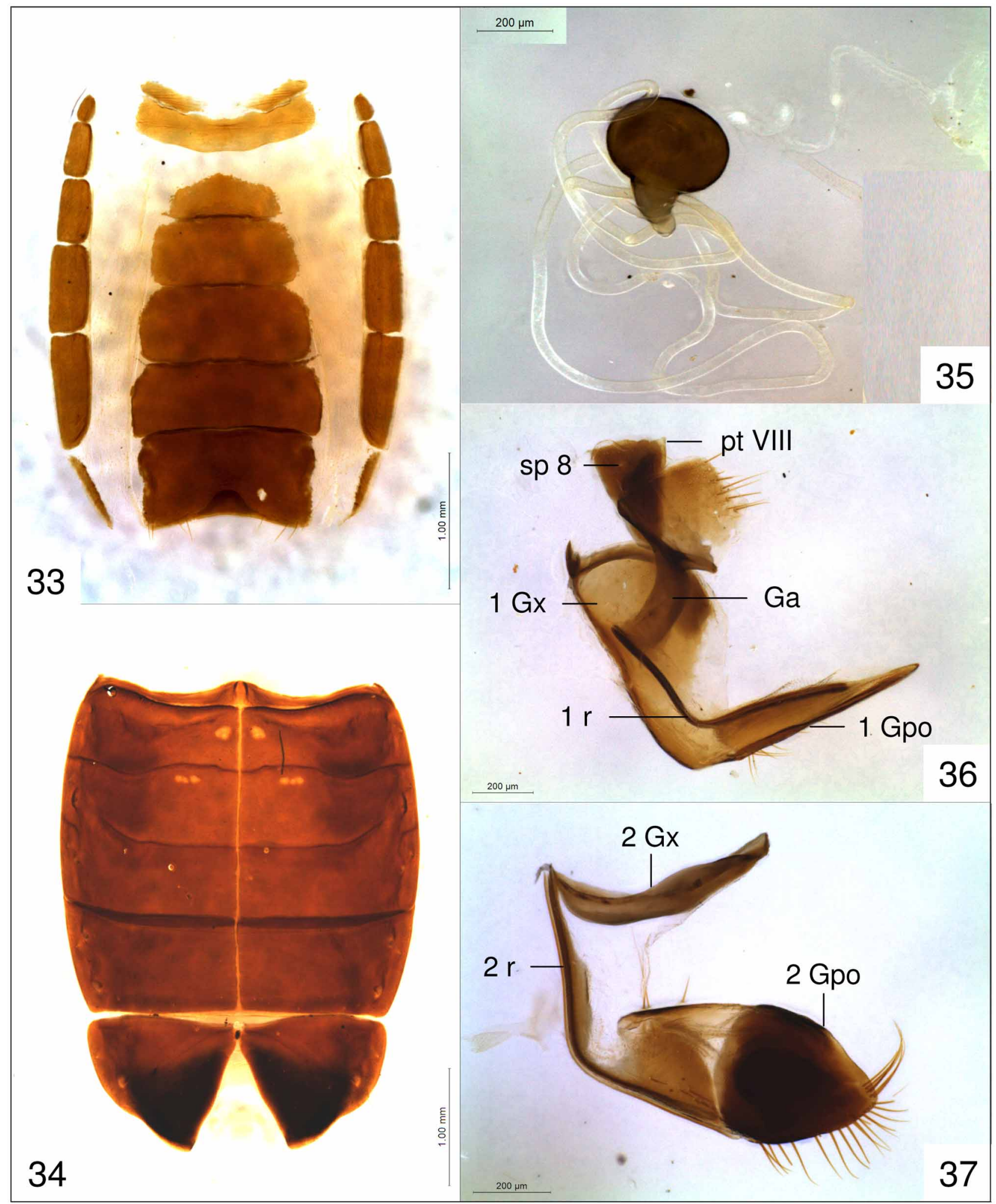

FIGURES 33-37. Laticlerada tasmanica holotype female: 33, abdominal tergum; 34, abdominal sternum; 35, spermatheca; 36, 37, first and second gonapophyses. Abbreviations: Ga, gonagulum; $1 \mathrm{Gpo}, 2 \mathrm{Gpo}$, first and second gonapophysis; $1 \mathrm{Gx}, 2 \mathrm{Gx}$, first and second gonocoxa; ptVIII, eighth paratergite; 1r, 2r, first and second ramus; sp8, spiracle of eighth segment.

Structure: Measurements are of holotype. Body (Fig. 28) broad and flat, shiny above, with rather short antennae; abdomen parallel-sided. Body length including wings 7.13; maximum width 2.57.

Head: Gradually narrowed from base to apex (Fig. 30), tylus rounded and well exceeding jugae, these narrowed; antennifers slightly projecting anterolaterad; ocelli small, clear; bucculae very short and indistinct; head 
ventrally and medially not grooved to base of head; head above corrugated and conspicuously swollen, not similarly punctuate as pronotum. Length of head 1.19; width across eyes 1.03 ; interocular space 0.62 ; interocellar space 0.80 ; eye-ocellar space 0.04; eye length 0.33 ; eye width 0.23 . Antennae (Fig. 32) short and stout, geniculate, 1 st segment with one-quarter of its length extending beyond apex of head, 4th segment slightly heavy, 2nd swollen towards distal end; length of segments: I 0.43; II 0.92; III 0.41; IV 0.96. Labium (Fig. 31) short, reaching mid coxae, 1st segment reaching to level of middle of eye; length of segments: I 0.64; II 0.60; III 1.15; IV 0.43.

Thorax: Pronotum (Fig. 29) roughly trapezoidal, with lateral margins only slightly sinuate; with anterior collar well demarcated and lowered; posterior margin straight. Anterior quarter to third, including calli, raised and impunctate, remainder with 3 depressed areas; entire surface almost uniformly punctuate, punctures obsolete towards posterior margin; median length 1.01; width at posterior margin 2.27. Metathoracic scent gland auricle prominently projecting above pleural surface, orifice directed posteriorly. Legs slender, all femora of uniform thickness, armed below with a few long setae in two rows on fore femora and in one row on other femora; hind basitarsus slightly less than $2 \mathrm{x}$ as long as distal 2 segments combined. Scutellum with a distinct median laevigate ridge, uniformly punctate; length 1.03; width 1.26. Clavus with coarse punctures as follows: an almost complete inner row adjoining corial margin, an almost complete middle row, and the area between middle row and claval anal margin covered with unevenly spaced punctures; claval commissure 0.87 . Corium almost parallel-sided, basal quarter slightly narrowed, then expanded and gradually narrowed posteriorly; vein $\mathrm{R}+\mathrm{M}$ distinctly carinate above corial surface; punctuate as follows: 2 more or less complete parallel rows adjoining claval margin (with an incomplete row between), 1 or 2 short incomplete rows exterior to outer row; remainder of corium covered with uniform, but unevenly spaced punctures. Length of hemelytra 4.60, length of corium 3.45; width of membrane 1.75 . Hind wings not examined.

Abdomen: Dorsally flat, ventrally medianly keeled (Fig. 34), subshiny; submedian trichobothria on stenum III in triangular series and those of sternum IV in rectilinear series; trichobothrial areas rugulose and raised above surface; intersegmental suture between III-IV curved indistinctly forward well before margin, but distinct on margin. Lateral tergites broad, except the last one which is long and thin (Fig. 33). Terga (Fig. 33) mostly membranous, with a broad median sclerotised patch gradually widening from about posterior half of 3rd segment to apex of abdomen (Fig. 33). Anterior scent gland scar slightly wider than posterior two scars, these equal in width.

Female: Ovipositor (Figs. 36, 37) short and broad; 1st gonapophysis narrowly pointed, with 1st ramus extending to about $2 / 3$ its length; 2nd gonapophysis very broad, oblong, abruptly narrowed to a conical point at distal end, with a few long upturned bristles; lower aspect of distal $1 / 2$ with sparse and shorter bristles as in Fig. 37. Spermathecal bulb large, spherical, heavily pigmented, with a basal neck but no basal flange; duct very narrow and with 4-6 loose coils (Fig. 35).

Male: Unknown.

Distribution. Tasmania.

Diagnosis. Laticlerada tasmanica is distinguished from L. nidicolloides Slater \& O'Donnell by the much shorter labium (reaching only to mid coxae vs. to beyond abdominal segment II, Fig. 31), and by the relative lengths of antennal segments II and IV (II shorter than IV vs. II longer than IV, Fig. 32). L. tasmanica is distinguished from L. laticollis Horváth by the uniformly narrow reddish-orange band across the posterior of the pronotum (Fig. 29, this band gradually widening towards the humeral angles in L. laticollis); and by the differences in head width to interocular space ratio (Fig. 30).

Etymology. This species, the first member of Cleradini to be described from Tasmania, is named after the type locality.

Notes. Laticlerada (now comprising eight species) is mostly known from eastern Australia (Malipatil 1983, Slater \& O’Donnell 1995, and the present study).

\section{Acknowledgements}

We thank Dr. Alan Eyles for providing valuable comments on the manuscript. 


\section{References}

Bergroth, E. (1914) On an Hemipterous insect from an Australian opossum's nest. Transactions of the Royal Society of South Australia, 38, 53-57.

Cassis, G. \& Gross, G.F. (2002) Hemiptera: Heteroptera (Pentatomomorpha). In: Houston, W.W.K. \& Wells, A. (Eds.), Zoological Catalogue of Australia. Vol 27.3B. CSIRO Publishing, Melbourne, Australia xiv 737 pp.

Horváth, G. (1909) Species generis Lygaeidarum Clerada Sign. Annales Musei Nationalis Hungarici 7, $622-625$.

Malipatil, M.B. (1978) Revision of the Myodochini (Hemiptera: Lygaeidae: Rhyparochrominae) of the Australian Region. Australian Journal of Zoology, Supplementary Series 56, 1-178.

Malipatil, M.B. (1981) Revision of Australian Cleradini (Heteroptera: Lygaeidae). Australian Journal of Zoology, 29, 773-819.

Malipatil, M.B. (1983) Revision of World Cleradini (Heteroptera: Lygaeidae), with a cladistic analysis of relationships within the tribe. Australian Journal of Zoology, 31, 205-225.

Slater, J.A. \& O'Donnell, J.E. (1995) A catalogue of the Lygaeidae of the world (1960-1994). New York Entomological Society, New York, 410 pp.

Sweet, M.H. (1967) The tribal classification of the Rhyparochrominae (Heteroptera: Lygaeidae). Annals of the Entomological Society of America, 60, 208-26. 